\title{
BUILT ENVIRONMENT: MODELLING THE URBAN SPACE
}

\author{
F. Guzzetti ${ }^{1}$, K.L.N. Anyabolu ${ }^{1}$, L. D’Ambrosio ${ }^{1}$, G. Marchetti ${ }^{1}$ \\ ${ }^{1}$ Politecnico di Milano, Dept. of Architecture, Built Environment and Construction Engeneering, via Ponzio 31 20133, Milano - \\ (franco.guzzetti, karenlara.anyabolu, lara.dambrosio, giulia1.marchetti)@ polimi.it
}

\author{
Commission II, WG II/8
}

KEY WORDS: BIM model, urban space, built, underground facilities, H-BIM, scan-to-BIM

\begin{abstract}
:
In urban areas, the "built" is defined by many different elements. Not only buildings but also open spaces containing green areas, viability, urban furniture, underground facilities. While the H-BIM sector focuses, rightly, on buildings of great historical significance, in our case it is been consider a part of the built that it usually not analyse: the urban open space. One of the interesting themes is the possibility of having a single tool that integrates the different objects present in a complex environment such as the urban area. The process with BIM model could allow a huge saving in terms of time and costs considering public tender, maintenance or construction phase of a project. Facility management operating through BIM is another relevant theme considering the whole life of a construction. Finally, another important theme is the connections between elements above the ground (visible elements) and subsoil (not visible elements), not only for the administrations but also if related to the HBIM environment.

The paper reports the analysis of the experience performed, particularly related to questions about detail and accuracy of the BIM model.

A methodology for modelling open spaces is been assuming, it is described possible improvements and considerations on the result.
\end{abstract}

\section{THE BUILT}

\subsection{Different meanings of built}

The built is a single word that contains many different elements. Considering an urban area, it could be said that everything is built, not only effective buildings.

In this urban environment, different types of architecture exist. Part of the constructions played an important role in history and they are extremely precious for the collectivity, but there are also ordinary buildings as factories or residential buildings that are not considered part of Cultural Heritage. On the other side, there is another type of built namely the open spaces, that included (in an urban environment) streets and sidewalks, car parking, green areas, squares, transportation path, urban furniture and facilities.

This second part of "built" is as important as the buildings in the construction and management of a city: every citizen experiences for itself connections and open places, and the quality of these spaces is important.

Talking about existing buildings it can be assumed that they have, physically, the same problems and needs; but the approach with which they are been study and analyze changes.

The historical buildings, in fact, are subject to rules of protection and conservation. In Italy, T.U. 42/2004 (Decreto Legislativo 22-01-2004, n. 42 "Codice dei beni culturali e del paesaggio") (and subsequent amendments), defines the cultural architectural and landscape heritage and stabilize constraints and possible interventions.

Based on this legislation, it requires that the life cycle of those architectures is analyzed in a detailed way and under many aspects. At the same way, refurbishment and conservation projects need to be controlled and verified, considering the history of the building.

The rest of buildings construction, falling outside the heritage buildings, constitutes the largest part of the urban environment and it is contributing to the definition of a city. Refurbishment and maintenance of these building are essential for the structure of the urban environment. (Figure 1)

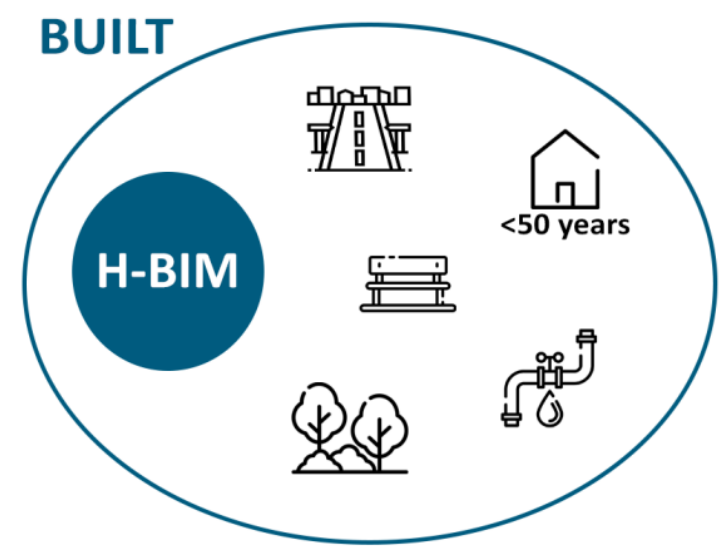

Figure 1. Scheme of the elements of the built environment

Starting from 2019, complex projects over 100 million $€$ that participate in a public tender, must present a BIM model. By January 2025 the use of BIM will be extended to any type of project, public and private, for new buildings and refurbishment (Decreto del Ministero delle Infrastrutture e dei Trasporti, 1-12-2017 , n. 560). This update will generate many advantages, even though it will be necessary to verify the correctness and completeness of the data rigorously. 
The same approach could be used to integrate and enrich the representation of urban open spaces.

Therefore, it is important to understand how the survey techniques can support, in an adequate way, BIM models of existing buildings and urban open areas.

\subsection{Urban Space}

In the building environment, therefore, buildings are not the only important portion. The other side of the built is the open space, that includes many different elements visible and notvisible, artificial and natural, fixed and mobile: it is a complex environment to analyze, with mixing of objects to considering. For instance, on the surface it possible to find, urban furniture, road signs, lighting columns, flowerbeds and natural object as trees, shrubs; the terrain instead can be a green area, road surface, with tram tracks or stones. The entire space is complete with all the elements of the underground, every network and connection that supplies water, electricity, energy and other facilities and services.

Thanks to the scan to BIM method, starting from a point cloud, it is possible to analyze and recognize in detail every object with a fast survey in the field.

This environment is rich in data and full with elements of different nature; it usually never been analyzed in an integrated way: this situation makes the organization difficult and it prevents optimal management from the administration. The implementation of new technologies could be extremely important for the development of survey techniques.

Particularly, using BIM model, the organization of competitive tender for urban renewal or simply maintenance of a small part, would be coordinated and verified with an evident saving of costs and better functionality for the whole city.

\subsection{H-BIM: current situation}

Nowadays, several studies utilized the SCAN-to-BIM process, for the definition of Heritage building 3D model. (Oreni et al., 2014)

The study of the cultural architectural heritage with the implementation of BIM modelling is a big challenge, particularly, for our country, where a quarter of the entire residential heritage consist of buildings raised before 1946 and 1.832 .504 buildings $(15 \%$ of the total of residential construction) are constructed before 1919. (ISTAT, General census of the population and the residences, 2011)

The development of HBIM allows to improving the process of consolidation and conservation project; it also possible to collect the data of various cases study and compare them to get significant statistics.

Most of all, the benefits regard:

- degradation monitoring thanks to continuous updating following different survey

- timeline of a conservation project, with the possibility to check the state of the building in every moment

- creation of a digital archive sharable worldwide
We must also take into account the BIM model exploitation for cultural dissemination activities: new technologies as VR and AR can promote and valorize historical buildings. (Banfi et al., 2018)

In the last years, new technologies and advanced knowledge allowed developing 3D model rich of detail directly from the point cloud (Tucci et al., 2018). The NURBS, Non Uniform Rational Basis-Splines, creates surfaces that follow with high precision the points generated by a laser scanner survey. (Barazzetti et al., 2015)

In many cases, the process is adequate to recreate a building, particularly in HBIM field.

On the contrary, it would be complicated using this process in open spaces.

This research tries to find another path to create a complex BIM model of urban space, considering the visible part and the underground.

\section{CASE STUDY}

\subsection{Urban Space Analysis and Survey}

The case study treats the analysis of an area in proximity of a road intersection near the Politecnico in Milan of about 2800 $\mathrm{m}^{2}$. The phases have foreseen the use of different technical equipment and software, from the laser scanner survey to the BIM modelling, to investigate the utility of a complete informative model for a public tender. (Guzzetti et al., 2018)

The whole research project is conducted in order to study a possible process for the creation of an open space BIM model. The aim is to understand the advantages of using an informative model that contains the total of present objects in urban space; currently, they usually result in conflict with each other because they are not managed in an integrated way. Furthermore, the link between objects on the surface and objects in the underground are an important theme in the research (Regolamento Regionale 15 febbraio 2010 n.6,"Criteri guida per la redazione dei piani urbani generali dei servizi nel sottosuolo e criteri per la mappatura e georeferenziazione delle infrastrutture", BURL).

In the hypothesis of refurbishment project or maintenance task is interesting using a comprehensive tool as a BIM modelling with numerous information, especially for the interoperability by several users. (Osello et al., 2018)

Nowadays public works in urban areas are thought in a separated way: for instance, a specific intervention on water pipe does not consider the interference with urban furniture or greenery maintenance in the same area. (Di Maria et al., 2009) In the same way, in case of urban renewal project, it found difficult to collect all the data about every single object, especially referred to facilities in the underground. The underground utilities are essential for the management and the activities of the city; they are underestimated, while it would be being desirable to consider them in a BIM model for the speed of consultation and for the cross-checking of multiple data. (Cattaneo et al., 2010)

Also, it should consider the interaction between built and the green; the BIM model is not only for quantification and description of the plant species but, using georadar, it is possible to verify the interferences in the subsoil of the roots with the present or planned elements or in case of a new project. 
Here it is described the entire process of how our team developed the BIM model from the point cloud related to an open space.

The first phase consisted of the analysis of the urban area, in order to organize the laser scanner survey with the support of geodetic network implemented for this case study. With @Faro Focus 3D HDR CAM 2 it was registered 26 scans with a density of 28 million points per scan, plus image acquisition. The process employed 7 minutes to scanning and other 7 minutes to obtain photos for each scan.

In order to join the scans and to georeference the point cloud, it was necessary registered checkboard targets and verify the positions of others spherical targets that are recognized in the software @Scene7.1 in the next stage.

After the fast survey on the field and the elaboration of data, it follows a phase related to extrapolation of vector profiles from the point cloud. This operation is been conducted with (C)Autodesk Autocad, in order to obtain guidelines for the construction of BIM model on CAutodesk Revit. In the majority of cases, it has created 3D polylines and geometric points (with coordinate $\mathrm{x}, \mathrm{y}, \mathrm{z}$ ) to report the correct position of the objects and the profiles of the surfaces in the area. For instance, it is drawn positioning point for lighting columns, manholes, trees, while the polylines define sidewalks, tram tracks and cables, and street.

\subsection{Modelling process}

The definition of BIM model was executed through a transition of information from (CAutodesk Autocad software, without using NURBS process utilized on HBIM for the buildings.

Subsequently, to an inspection visit, it is confirmed the presence of several disturbing elements both mobile and fixed, as persons, vehicles, public transports that create high noise in the cloud. Moreover, there are all the other objects that prevent clear visualization of the surface but they are necessary to survey and, in a second time, to model. Furthermore, one of the main aims is to recreate the objects in the underground; due to this operation, it is been decided to create terrain objects directly with stratification and attributes using the component "slab" in CAutodesk Revit.

During the verification of the point cloud, a cleaning is initially effect with the software (CAutodesk ReCap in which it is possible to delete parts of the cloud to ease the file .rcp. Through this operation, it finds complicated identify clearly the paving shape because of the interference with objects, the incorrect laying of the applied materials and in the green areas for the presence of vegetation.

The creation of the elements has been performed planning horizontal and vertical sections based on the necessity. As regards the terrain, it is interesting to study the transverse slope of the street: by setting horizontal section plans with $2 \mathrm{~cm}$ interval it can obtain thin slices of the cloud. By tracking a polyline along the average of the visible points it is possible drawing the level curves; in this way, it is fastened clear the profile of the street and consequently, for instance, the direction of the water flow.

Regarding vertical sections, the interval length is $1 \mathrm{~m}$, in this way it possible to follow the correct course of sidewalks.

Subsequently, it is described in the specific, the method experimented with relative both problems and solutions.

\subsection{Methodology}

Operating at this level, it finds difficult to define the accuracy between the point cloud and the final BIM model. What is the precision required? Are there several elements that are not necessary to represent?

The starting point for the model is a point cloud, with a precision of $\pm 2 \mathrm{~mm}$ in according to the initial settings of point density; every object is detected in a three-dimensional way (thanks to the several scans registered). Despite this high precision, it will always need to individuate an average point to define a vertex or a corner; this should be taken into consideration because the difference between a point cloud and a parametric model is due to the level of accuracy and precision required.

The rule that is worth in absolute regardless of precision and LOD in the modelling construction, is to follow the topology rules. The same methodology used in the creation of geodatabase, is essential to create a model with correct interaction between objects. Every point and every surface must correspond perfectly to avoid errors during the process.

\subsection{Precision and accuracy}

The research project was testing about modelling an urban open space, therefore there were no particular pre-defined constraints. The level of precision and accuracy (do not confuse with the level of detail) is defined based on different considerations done during the analysed work.

Depending on the purpose, it is necessary to understand at what level of precision an irregular object should be modelled (for example the representation of a curved slab or a wall out of plumb that in some cases may be fundamental data) considering that $($ Autodesk Revit was born as a program for new buildings' modelling based on orthogonal planes. (Barazzetti et al., 2018)

Other elements to consider are the followings:

- in the area, there are clearly visible errors of laying of the materials; they have to be analysed with attention: is it necessary to model a manhole protruding in comparison to the bituminous mantle or a stone slightly inclined?

- the placement of the objects it is more difficult on irregular surfaces that are not perfectly parallel to section plans, especially for englobed elements. (C)Autodesk Revit is optimized for regular elements thus it tries to rectify surfaces where is need to insert particular objects as manholes;

- it is essential to consider that the model, to be useful, has to be a lightweight file and within the reach of as many operators and common people as possible;

Surely, many of these irregularities are useful to organized maintenance intervention, but overall it could be more easily insert this kind of data as a new attribute embeddable in case of need.

The point to take count is the final goal of the model: in the research, it is hypothesized the use of the model for a competitive tender for urban renewal, therefore, the information has to be correct, not the necessarily the model.

In H-BIM it required a high level of precision and accuracy in 
order to study structural elements, materials and construction method.

Instead, in this case study, some of the most important information is the position of elements in the space, the dimensions of paved areas (to know the quantity of material), the terrain slope to define the direction of drain water (with verification of point of storm drains).

All things considering, it defines the approximation of the model. (Figure 2)

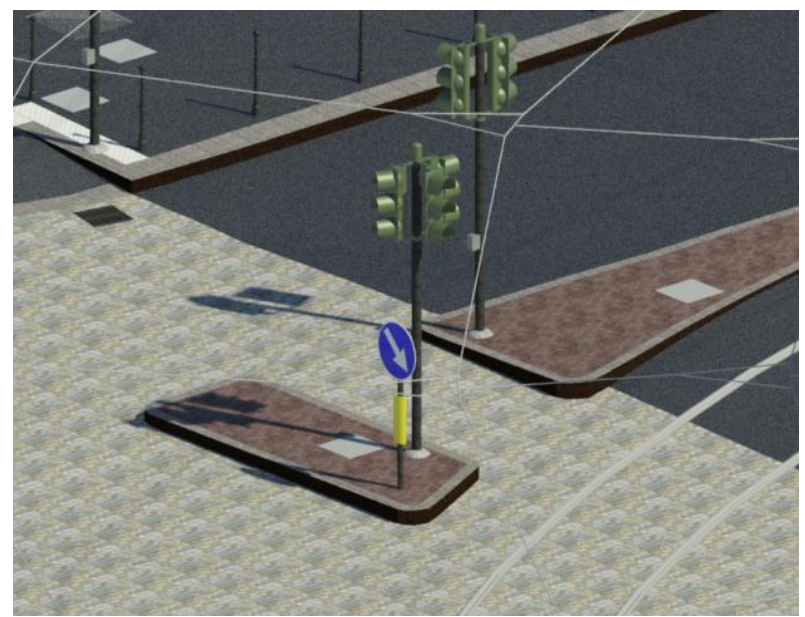

Figure 2. Image of the final BIM model with different paved areas integrated with the objects of urban spaces

\section{MODELLING}

\subsection{Object modelling: families}

Another problem is related to the creation of the objects to insert inside the modelled environment. As it is known, the open source libraries are little provided and the greatest part of the existed elements are English or American objects and therefore not correspondents to the Italian legislation.

Furthermore, it is necessary to guarantee (over legislation) that all the BIM objects make reference to a shared standard of parameters of information and with a level of efficient geometric detail as declaimed, for instance, by BuildingSMART. (BuildingSMART International. IFC Overview Summary. 2012)

The National BIM Report 2018, collects data on the major standards used and the main sources of information about BIM.

There is the necessity to create and to implement libraries of files that allows the interoperability with the different software BIM. (Lopez et al. 2018)

As a practical example is described the creation of a traffic light constituted by pole and traffic light corps, with all the parametric data.

The object is been model starting from the point cloud and the direct survey for parts not well visible in the cloud due to interferences or obstacles. At the same way as paved areas, the element is directly defined and model thanks to sections on the cloud on (C)Autodesk Autocad.

There are not been created mesh or NURBS using other software.

Despite is difficult to find a default object, however, it concerns a standard element. For this reason, it is convenience to treat the object as a new model whose profiles are extrapolated from the cloud (with vertical and horizontal sections). The drawn profiles indicate the dimension, and during the phase of modelling the editable parameters are inserted: height, diameter, the quantity of traffic light corps, their angle of pose (Figure 3).

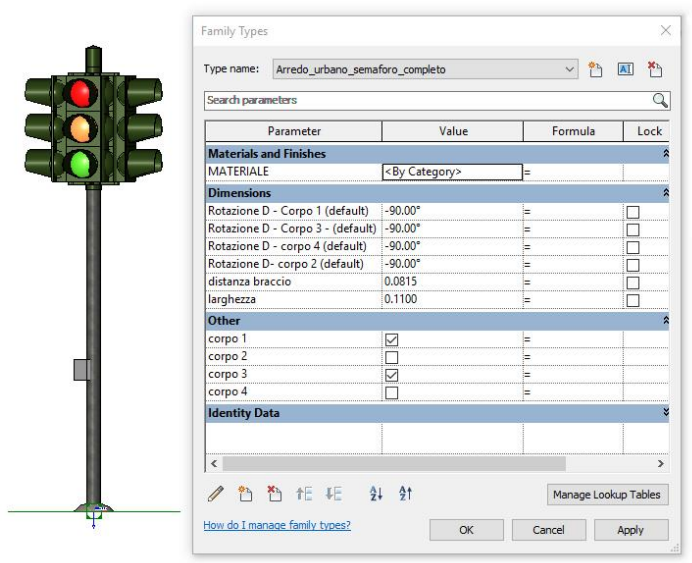

Figure 3. Family of a traffic light with the table of parameters

The traffic light corp is treated as a "nested family" in whose are been modelled other components. Potentially, the elements created can have inside other families, with significant information useful to the maintenance of the product; for instance, data about type and duration of bulb light. Furthermore, it is possible to add other separated objects as webcam or sensor.

During the modelling of a family, in this case, it is not excessively important the perfect overlapping with the point cloud (precision). As said above, considering standard elements, it is more interesting having all the single parts even they are not precise, especially given the importance to have data applied to the objects.

It is preferable to have the number of light bulbs and hooks rather than knowing, with high accuracy, their geometric shape. Once determined what to represent and which LOD is needed to reach, it is noted that, in the case of urban open space, the greatest part of the elements are mass produced.

In the future, these objects should be made available directly by suppliers or in open library as actually happen with downloadable .dwg files.

This would be an advantage both for the use of an object with correct and complete attributes and for economic quantification of the object or parts of it. Obviously, the common logic and shared platform are necessary to get coherent and suitable elements. (Lopez et al. 2018)

\subsection{Object modelling: slab}

As explained before, the pavement is been create as a slab with related stratigraphy and parameters. The aim is to create a component with a specific stratigraphy, considering that will be inserted object families in the subsoil (for example, it is interesting to know the depth of the ground under the layer of stones).

The most effective command to realize a solid with an irregular surface is "roof" (on (C)Autodesk Revit), that allows creating elements tilted with more facility.

To the level of correctness of the model however it is held more adequate using the component "slab" in order to verify the modelling arrangements of a surface not perfectly plan, 
maintaining its identification inside the program @Autodesk Revit.

The upper part of the pavement is been modify moving the anchorage points and grab them in correspondence of the polyline 3D points used as guidelines (Figure 4)

It is been tried to simplify the geometry and reduce the number of triangles per object, so as not get a heavy file, maintaining the necessary information based to the aim (for instance the slope to know the direction of water flows).

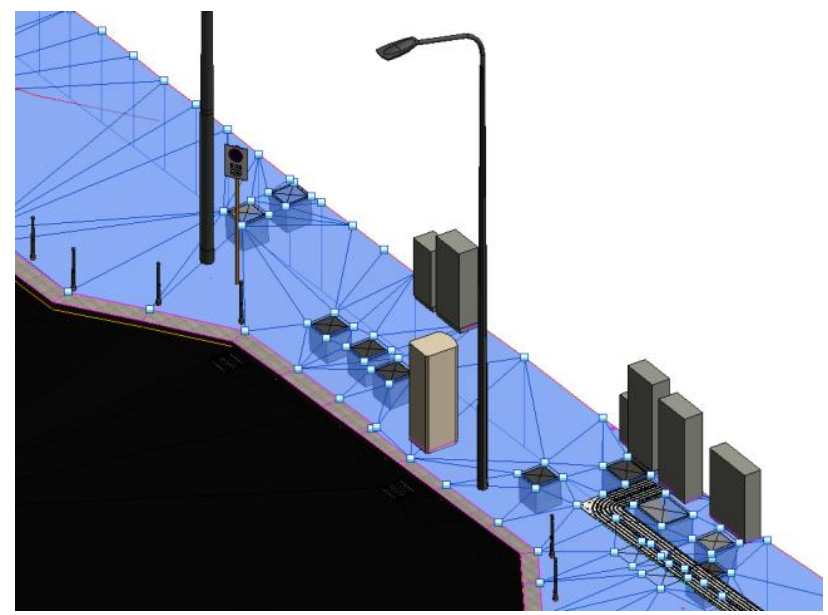

Figure 4. In evidence, the component slab with anchorage points used to create the paved areas

\subsection{Modelling the underground}

Another phase during the research, it is been the identification and modelling of underground facilities.

The mechanical parts are been represent using GIS data integrated with manholes survey. The networks are been schematize on software (CAutodesk Autocad; the indicative sketch of the connections in the underground is made possible investigating the different typologies of existing manholes. On (C)Autodesk Revit it is been necessary work in the MEP section in order to define types of pipe and relatives dimensional attributes.

The existing networks are numerous and independent the one from the others, there is only a physical interaction between the infrastructures; in the case of a renewal project, to this purpose, it is useful a clash detection for an integrated study of networks.

The connections are two different kinds: the rigid pipes with precise sizing based on the flow rate and the section under examination; and the flexible corrugated pipe that contains several cables as electrical, optical fiber, telephone. This part of the BIM model can be considerate one of the most important for comparison between the information represented and real information.

In many cases, the data could be found in a topographic database working with .shp (in GIS environment). However, it has to consider that the precision of a DBT is between 30 and $40 \mathrm{~cm}$ and in this particular situation having a scheme that starts from the correct position (accuracy of the laser scanner survey) of manholes and terminals is a considerable advantage.

After all, it is reminded that the realistic visualization together with geometries, materials, greenery and urban furniture allows a fast and clear comprehension.
Finally, in the phase of the project, the computation and the presentation of the urban renewal are immediate.

\section{LINKS WITH H-BIM}

In built environment, many open spaces can have a great historical value. Our team works on a portion of a street, but the same process is developed and the same problems arise considering a heritage area as a square or a path inside the old town.

For instance, studying the construction of a church, it is interesting analysed the parvis with its historical pavement but also counting urban furniture and underground facilities.

Furthermore, the interconnections between historical buildings and environmental context are fundamental, especially in the case of several buildings adjacent to each other, where the road is an essential part to analyse the situation.

The work done concerns a small portion of a square in an urban context, which considers the subsoil up to $2 \mathrm{~m}$ of depth and the space above up to $10 \mathrm{~m}$ at high altitude (it has been model street lights $8 \mathrm{~m}$ height and tram cables).

Despite the small size of the area, different problems it has been faced; probably it has been analysed the greatest part of the elements existing in a common urban area (counting car sharing area, totem, stop for recharge electric vehicles).

At this point it could be interesting, apply this approach to represent open spaces related to heritage building, both internal and external paved areas.

It is possible modelling the paving through the component slab, as said before, to represent not only the surface but even the stratigraphy, that can be extracted by non-destructive investigations.

Furthermore, the integration of the facilities in the subsoil can be hypothesized. In this case, at least three advantages could be count:

- having a representation of the existing underground structures, in order to have important information for a consolidation or conservation project to the building;

- possibility to project new mechanical parts considering the existing elements and using the available spaces;

- constant updating of information for maintenance through time

The difference between a common drawn scheme and a BIM model is that the second one (with its extension ifc) can be used immediately by different figures, to project and to know the dimensions and passages of the facilities.

The interoperability, working in BIM, is a significant and positive change for the entire process.

\section{CONCLUSIONS}

The paper described a way to work with growing technology as laser scanner survey and BIM model on urban open spaces. This particular subject, the open space, is not considered so remarkable if compared to the buildings, especially historical buildings, even if it results an important part of the built. 
For this reason, the research tries to investigate the advantages of a BIM model constituted of objects situated above and under the ground.

In summary, it is important to have the awareness to be able to improve the future phases of urban renewal and maintenance in the city open spaces, through the use of an informative model constantly adjourned. Hypothesizing the collaboration of different users (considering that BIM model is an obligatory request for every type of building intervention by 2025), it is possible to think to an interesting development of the theme analysed. The creation of parts of public space next to the buildings together with the management of facilities and green by specialised companies, can define a complete database.

\section{REFERENCES}

Banfi, F., Stanga, C., Brumana, R., 2018, A Digital Workflow for Built Heritage: From SCAN-to-BIM process to the VR-Tour of the Basilica of Sant'Ambrogio in Milan, 7th International Conference, EuroMed 2018, Nicosia, Cyprus, October 29November 3, 2018, Proceedings, Part I

Barazzetti, L., Banfi, F., Brumana, R., Previtali, M., 2015, Creation of Parametric BIM Objects from Point Cloud using NURBS, The Photogrammetric Record 30(152): 339-362 (December 2015) doi: 10.1111/phor.12122

Barazzetti, L., Brumana, R., Della Torre, S., Gusmeroli, G., Schiantarelli, G., 2018, Point clouds turned into finite elements: the umbrella vault of Castel Masegra, IOP Conference Series: Maerials Science and Engineering 364012087

Cattaneo, N., Di Maria, F., Privitera, A., Guzzetti, F., Viskanic, P., 2010, Terreno Comune, ACER n 6/2010, pag 51, 53 Verde Editoriale

Di Maria, F., Guzzetti, F., Privitera, A., Viskanic, P., 2005, Progetto verde Milano: "il censimento e la gestione del verde con strumenti Web Gis", $9^{\circ}$ Conferenza Nazionale ASITA, Catania

Guzzetti, F., Anyabolu, K.L.N., D’Ambrosio, L., Marchetti, G., Sarrecchia, S., 2018. Dal rilievo al modello BIM di una piazza, XXII Conferenza Nazionale ASITA, 27-29 novembre 2018, Bolzano, 577-584

Lopez, F.J., Lerones, P.M., Llamas, J., Gomez-Garcia-Bermejo, J., Zalama, E., 2018. A review of Heritage Building Information Modeling (H-BIM), Multimedial Technologies and Interact, 2018, 2, 21; doi:10.3390/mti2020021

Osello, A., Ugliotti, F.M., De Luca, D., 2018, Il BIM verso il Catasto del Futuro potenziato tramite l'utilizzo della tecnologia, doi:10.26375/disegno.2.2018.15, 135-146
Oreni, D., Brumana, R., Banfi, F., Bertola, L., Barazzetti, L., Cuca, B., Previtali, M., Roncoroni, F., 2014 Beyond Crude 3D Models: From Point Clouds to Historical Building Information Modeling via NURBS, Lecture Notes in Computer Science, November 2014

Tucci, G., Bartoli, G., Betti, M., Bonora, V., Korumaz, M., Korumaz, A.G., 2018, Advanced procedure for documenting and assessment of Cultural Heritage: from Laser Scanning to Finite Element, 2018 IOP Conference Series: Maerials Science and Engineering 364012085 